\title{
50. IDENTIFICATION AND PROTECTION OF EXISTING AND POTENTIAL OBSERVATORY SITES*
}

\section{(PROTECTION DES SITES D'OBSERVATOIRES EXISTANT ET POTENTIELS)}

PRESIDENT: M. F. Walker

VICE-PRESIDENT: R. Cayrel

ORGANIZING COMMITTEE: C. A. Anguita, F. Bertola, A. Blaauw, H. A. Brück, D. L. Crawford, H. Elsässer, S. C. B. Gascoigne, W. Mattig, S., van den Bergh.

\section{INTRODUCTION}

One of the most serious problems facing astronomy today is that of the deterioration of ground-based observing sites due to the effects of atmospheric pollution and electromagnetic radiation. In response to this problem, the IAU, at the last General Assembly in Sydney, created Commission 50 on the identification and protection of astronomical observing sites. Since the problems of site identification and protection are very different in the fields of radio and optical astronomy, and since protection of radio astronomy is already being handled by IAU Commission 40 and the Inter-Union Committee on Frequency Allocations, Commission 50 is concerned only with the problems of optical astronomical observations. In the field of optical astronomy, the conditions required for optimum solar observations likewise differ substantially from those for dark-sky stellar observations. For this reason, and because solar sites are less threatened with deterioration than stellar sites - being affected only by atmospheric and radio-wave pollution and not by the light pollution so damaging to the latter - the activities of the Commission have so far been restricted exclusively to the problem of dark-sky stellar observing sites.

Owing to the special nature of this Commission, the membership of the Commission consists of: (1) an Organizing Committee, consisting of (a) individuals actively working in the field of site investigation and protection and (b) representatives of major national and international observatories. (2) National Representatives, appointed by the National Committees of member countries of the Union, who form the general membership of the Commission. To date, 25 countries have appointed delegates to the Commission.

\section{PROTECTION OF EXISTING SITES}

The role of the Commission in the protection of existing sites is intended to be three-fold: (1) In collecting and disseminating information regarding site protection measures being considered or that have been adopted. (2) In recommending types of protective actions to be taken. (3) In supporting protection measure for specific sites.

Many existing observatories are located close enough to major population centers to be adversely affected by their illumination. For example, in California, the visual sky brightnesses at Mount Wilson, Mount Hamilton, and Palomar Mountain are currently about 16, 4, and 1.4 times the natural level, respectively.

In order to determine the extent to which present observatory sites are now or are potentially affected by light and atmospheric pollution, what control measures have been undertaken or are contemplated, and what assistance the IAU might give in these efforts, circular letters were sent to the Directors of 16 institutions operating major astronomical observing facilities and to the National Representatives on Commission 50, or the National Committees, of all member

*Contributions from the Lick Observatory, No. 409. 
countries of the IAU. From the replies received (seven from the Directors and nine from the member countries) it appears that attempts to control or prevent the development of pollution at observatory sites are presently underway in only eight countries: Brazil, Canada, Chile, Denmark, Israel, Mexico, Japan, and the U.S.A. The other replies were about equally divided between those who reported that no pollution problem presently exists at their observatories and that no control programs are contemplated, and those who state that a problem exists but either the problem is too severe, or the observing conditions are too poor to make the institution of control measures feasible.

The most extensive efforts to control light pollution have been made in the U.S.A. A booklet on 'Observatories and Outdoor Lighting' by A. A. Hoag and A. R. Peterson has been published and distributed by the Kitt Peak National Observatory, and a Committee on Air, Light, and Radio Pollution has been set up by the American Astronomical Society under the chairmanship of Dr D. Crawford. Legislation controlling outdoor lighting has been adopted by Coconino and Pima Counties and the city of Tucson, Arizona, the county of Hawaii in the state of Hawaii, and by the city of Richland, Washington. In addition, the state of Arizona has passed an enabling act providing authority for regulating lights in areas surrounding astronomy or meteorology laboratories. At the request of Dr J. Jeffries, Director of the Mauna Kea Observatory, a letter was written giving Commission support to the passage of the Hawaii legislation.

The provisions of all of the lighting ordinances listed above are similar, and involve the shielding of lights to prevent direct radiation to the sky, filtering to remove wavelengths shorter than $4400 \AA$, and the regulation of searchlights used for advertising purposes, the illumination of outdoor public recreation facilities, and the illumination of advertising signs and the exteriors of buildings. Texts of these ordinances are included in 'Observatories and Outdoor Lighting', and the text of the ordinance adopted by the city of Tucson was published in the IAU Inf. Bull. No. 33, 1975, as an example of this type of legislation. These ordinances appear to be satisfactory as models of control legislation, except in one respect. With the exception of the Richland Ordinance, which limits new lighting of streets, parking lots, and other area-type lighting to clear mercury vapor with filters to remove wavelengths shortward of $4400 \AA$, these ordinances make no attempt to control the types of lamps used for outdoor illumination. The newer color-corrected mercury vapor, metal halide, and high pressure sodium lamps now coming into use produce irregular continua and in some cases numerous emission lines which, even with filtering, will contaminate the green, yellow, red, and near-infrared regions of the spectrum much more than clear mercury vapor (which, with filtration, produces emission lines at only 5461,5770 , and $5791 \AA$ ), low pressure sodium (which produces essentially only the $D$ lines in emission) or incandescent (which produces a uniform continuum, easier to remove by subtraction). Consequently, it would be desirable for observatories attempting to institute lighting control legislation to include in that legislation restrictions on the types of lights used to filtered incandescent and either filtered, clear mercury vapor or low pressure sodium.

Since economic factors enter very largely into questions of lighting control, it should be noted that the luminous efficiencies of the major types of lamps used for outdoor illumination, in lumens/Watt, are: incandescent 17 , mercury vapor 60 , metal halide 80 , high pressure sodium 120 , and low pressure sodium 180.

In the U.S.A., the cost of adding shields to new or existing lights to prevent direct radiation to the sky is about $\$ 20$ per lamp, while the cost of providing filters to absorb radiation shortward of $4400 \AA$ is about $\$ 20$ to $\$ 30$ per lamp. One benefit to the cities from the shielding of lamps used for street lighting is that it reduces the 'veiling glare' which results from looking directly at the light source and which reduces the ability of the eye to see. The California State Highway Department has added shields to lamps on the state highways to reduce this problem and improve driving safety.

In Brazil, efforts are being made to prevent site deterioration at the new National Astrophysical Observatory at Brasopolos and the Radio Astronomy Observatory at Itapetinga. Legislation now being considered by the National Congress would control outdoor illumination within a radius of $67 \mathrm{~km}$ of the Brasopolos site and forbid polluting industrial installations 
within a radius of $133 \mathrm{~km}$. Agriculture and non-polluting sophisticated industries will be encouraged within this restricted zone. At the request of Prof. L. Barreto, Director of the National Observatory, letters supporting this legislation have been sent by the Commission to the Ministry of the Interior of Brazil.

In Canada, as a result of efforts by the astronomers of the David Dunlap Observatory, lighting control legislation, patterned on the American ordinances discussed above, is currently being considered for adoption by the city of Richmond Hill. The David Dunlap astronomers have also been successful in changing the lighting design of two major highways to be constructed near the observatory, and in preventing the construction of a domed stadium and the change of street lighting from incandescent to high pressure sodium in the city of Toronto.

In Chile, Dr V. M. Blanco, Director of the Cerro Tololo Interamerican Observatory, is attempting to have legislation adopted, patterned upon the American ordinances, which would control outdoor illumination within a radius of $40 \mathrm{~km}$ of Cerro Tololo. To date, these efforts have resulted only in instructions by the Government to municipal officials who grant permits for electrical installations to take the provisions of this proposed legislation into account when approving new lighting.

In Denmark, efforts are being made to protect the observing conditions at the Brorfelde Observatory through the establishment of ordinances controlling light and atmospheric pollution in the vicinity.

In Israel, efforts are underway to protect the Wise Observatory from the effect of city lights of Mizpe-Ramon, five $\mathrm{km}$ distant, through the installation of shields preventing radiation above the horizontal.

In Mexico, a governmental decree was published in February, 1975, controlling activities in the San Pedro Martir Forest Reserve and National Park, in which the new San Pedro Martir observing station of the National Astronomical Observatory is situated. This decree prohibits all activities within the Forest Reserve and Park which might adversely affect the operation of the Observatory, but does not control light and atmospheric pollution from cities or areas outside its boundaries.

In Japan, no ordinances have as yet been passed for the protection of observatory sites. Efforts have been made by the astronomers of individual observatories to protect their sites through discussions of their specific problems with the officials of the neighboring cities, as well as the national government. Brochures have been printed to assist in these campaigns, which have had some success.

The effect of city lights on sky brightness depends upon distance, population, and economic factors (Walker 04.082.043, 10.082.108; Bertiau, et al. 09.082.121). ${ }^{*}$ Likewise, the acceptable level of light pollution at an observing site depends upon the type of research contemplated. Thus, the specification of allowable limits of illumination and of the size of region within which lighting should be controlled is difficult, and requires further study. The work by Walker and Bertiau, et al., suggests that in order to prevent artificial illumination of the sky in excess of $10 \%$ above normal, lighting controls should be imposed within a radius of $60-100 \mathrm{~km}$ of the site. However, in practice such control may only be possible in a few cases. Since any reasonable control measures cannot completely eliminate light pollution, it is clear that even with light control programs the more severely affected sites will still have substantial sky illumination, which is likely to grow with time as population levels in their vicinities increase.

Additional study is also needed to set definitive standards regarding the amount of radio frequency emission that can be accepted at the site of an optical observatory. However, present information suggests that a flux level of $1 \times 10^{-5} \mathrm{~W} \mathrm{~m}^{-2}$ can be tolerated without interference with electronic equipment presently used in stellar astronomy.

Control of atmospheric pollution is now being actively pursued in many localities because of health considerations. It is clear from these efforts that the problem is an extremely difficult one and the degree of improvement that can be expected is uncertain. Save in exceptional cases, there appears little that the IAU can add to the work that is already being done in this area.

*In this report, references are given, where possible, in terms of the number of the paper in the Astronomy and Astrophysics Abstracts. 


\section{IDENTIFICATION OF POTENTIAL OBSERVING SITES}

As discussed in Section 2, the nature of the problems of light and atmospheric pollution are such as to make control difficult or impossible at many of the presently established observatory sites. Thus, more and more there will be a need to supplement or replace these sites with dark sky locations. Consequently, there is an urgent need to identify the best remaining sites for dark-sky stellar optical astronomy, to take steps now to preserve them for future astronomical use, and to prevent their deterioration through the development of light and atmospheric pollution in their vicinities. This problem is of particular importance since, as will be discussed below, it now appears that very special conditions are required for the best observing sites, so that the number of potential sites of the very highest quality may be very small and represent a limited and non-renewable world resource.

While agreeing with the need for such a world-wide study, the Executive Committee of the IAU has determined that the Union can not itself undertake such a program owing to the financial cost involved. Commission 50 has explored a number of alternate sources of financial support for this work, but without success. It is clear, therefore, that the investigation of potential sites will have to be undertaken on a case-by-case basis as opportunity permits, and that the costs of such studies will, in most cases, have to be met by the country in which the site is located. The role of the Commission in this area will be fourfold: (1) In analyzing the conditions required for the best observing sites and in helping to designate those areas which should be investigated as potential observatory sites. (2) In supporting the efforts of countries or astronomical observatories or groups to organize and carry out site investigations. (3) In assisting these countries and astronomers to protect the best identified potential sites from future light and atmospheric pollution. (4) In acting as a clearinghouse for information concerning site investigation programs that are undertaken and the results obtained.

\section{A. Requirements and Locations for Optimum Dark-Sky Observing Sites}

In keeping with (1) above, it is appropriate to review here our current understanding of the requirements and most probable locations for the best dark-sky observing sites. The characteristics in an optimum dark sky observing site include:

(1) Highest possible percentage of clear weather.

(2) Maximum number of hours of astronomical darkness.

(3) Dark Sky.

(4) High transparency.

(5) Minimum optical turbulence.

(6) Location to minimize future deterioration due to light and atmospheric pollution.

The general areas of the earth with the least daytime cloud cover can be identified by means of the data now available from meteorological satellites, such as that contained in the Global Atlas of Relative Cloud Cover 1967-1970, published by the United States Department of Commerce and the United States Air Force. A study of this Atlas indicates that in broadest terms, minimum average cloud cover occurs in two latitude zones around the world, ranging from about $10^{\circ}$ to $35^{\circ}$ or $40^{\circ}$ north, and $0^{\circ}$ or $10^{\circ}$ to $35^{\circ}$ or $40^{\circ}$ south, depending on longitude. These areas are shown on the World map reproduced in Figure 1, where the shaded portions indicate regions having more than two octas of cloud cover at least 50 percent of the year.

An upper limit of about $40^{\circ}$ in latitude is also set by the requirement of having the maximum possible number of hours of astronomical darkness; beyond $40^{\circ}$, that number - and particularly the duration of astronomical darkness near mid-summer - decreases significantly. This limit is indicated by the dashed lines in Figure 1.

To have a dark sky, it is necessary that the observing site be located sufficiently far away from artificial light sources and, if possible, in an area where the future development of such illumination can be rigorously controlled. Locations with dark skies can be chosen from satellite photographs (Hoag et al. 10.082.107; Walker 10.082.108), or by constructing maps of 
the regions of light pollution produced by cities based on their population (Walker 04.082.043, 10.082.108) and economic development (Bertiau et al. 09.082.121).

High transparency requires that the site be located upwind from major sources of atmospheric pollution and at an altitude sufficient to place it above the height to which dust and aerosols are carried by convection from the surface. However, except in the case of sites for observations in the infrared region of the spectrum where as high an altitude as possible is required to minimize atmospheric water vapor, the altitude should not, if possible, exceed a value of about $3000 \mathrm{~m}$ or $10,000 \mathrm{ft}$ to avoid the problems of reduced working efficiency and acclimatization of visiting observers to the high altitude, and of severe meteorological conditions.

Our understanding of the conditions required for minimum optical turbulence of best astronomical seeing has been considerably enhanced by studies that have been conducted in recent years: Walker 04.082.043, 06.082.071; McInnes et al. 11.082.018; McInnes and Walker 12.082.033; Birkle et al., Astron. Astrophys. in press; and the results of the French Site Survey Work published by the Institut National d'Astronomie et de Geophysique, Observatoire de Meudon. It now appears that the basic requirement for minimum turbulence is that there be a laminar flow of dry, stable air over the site. Such conditions are found on the eastern side of the oceanic high pressure cells (or anticyclones) where cold ocean currents aid in the formation of maritime tropical stable (mTs) airmasses. These airmasses have several characteristics which tend to produce good astronomical observing conditions: (1) The upper portions of these airmasses are characterized by subsidence and divergence which produces stability against vertical disturbances (turbulence), and lowers their relative humidity. (2) The subsidence of the airmass leads to the formation of a subsidence inversion which limits the upward transport of surface air containing dust or aerosols; the air above the temperature inversion is exceptionally dry and clear. (3) Owing to their maritime origin, these airmasses have:

(a) A lower aerosol content and thus lower extinction than continental air.

(b) A more laminar flow than is found over continents where the flow is disturbed by the land forms over which it passes.

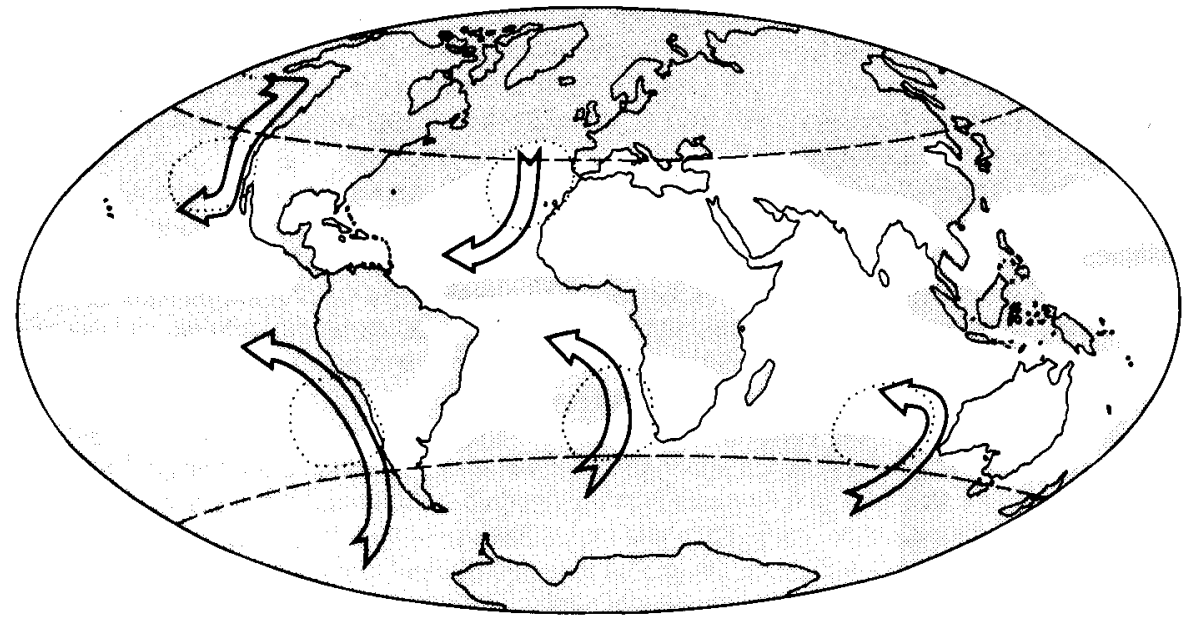

Fig. 1. World map showing areas with more than two octas cloud cover at least $50 \%$ of the time annually (shaded), cold ocean currents (arrows), and approximate boundaries of the regions of maritime, tropical, stable air (dotted lines). Latitudes $40^{\circ} \mathrm{N}$ and $\mathrm{S}$ are indicated by dashed lines.

These conditions occur in five regions around the world as shown in Figure 1, where the major cold ocean currents are shown by arrows and the approximate boundaries of the mTs 
airmasses by dotted lines. Since the upper-level circulation pattern is generally west to east, the mTs airmasses tend to be carried onshore on the continents bordering the airmass source-regions on the east, so that good observing conditions should be found in the first range of coastal mountains, where the laminar air-flow set up over the ocean still persists. Thus, the best sites should be found on mountain peaks rising above the inversion layer:

(1) In the eastern Pacific Ocean and along the west coasts of California and Baja California between latitudes $40^{\circ}$ and $20^{\circ}$ north.

(2) In the eastern Pacific Ocean and along the west coast of South America between latitudes $20^{\circ}$ and $40^{\circ}$ south.

(3) In the eastern Atlantic Ocean and along the west coasts of the Iberian Peninsula and Africa between latitudes $40^{\circ}$ and $20^{\circ}$ north.

(4) In the eastern Atlantic Ocean and along the west coast of Africa between latitudes $20^{\circ}$ and $33^{\circ}$ south.

(5) In the Indian Ocean along and off the west coast of Australia.

In addition to being located in one of these areas, the peak and its surroundings should present a convex profile to the impinging airflow to minimize turbulence in the airflow over the site, and to avoid transport over the site of bubbles of cold air formed by contact with the slopes of the mountain during the night.

These conditions suggest that the very best sites may be found on islands in the above regions, rather than on continental coasts; not only is the air-flow likely to be more laminar at an island site, but the danger of light and atmospheric pollution will be less and more amenable to future control.

\section{B. Present Information Concerning Potential Island Sites}

The number of possible island sites in these areas is very small and, as a result the site testing work done by the Royal Observatory Edinburgh for the British Northern Hemisphere Observatory and reconnaissance work by the writer, we now have at least some information about conditions at all of them.

There are no suitable islands at all in the Indian Ocean West of Australia, or in the eastern part of the South Atlantic. In the Pacific, only two islands have the proper location, shape, and altitude of peak. These are the islands of Guadaloupe $\left(\lambda=118^{\circ} 15^{\circ} \mathrm{W}, \phi=29^{\circ} 00^{\prime} \mathrm{N}\right.$, altitude of peak $1300 \mathrm{~m}$ ) located about $250 \mathrm{~km}$ west of the coast of Baja California, and Alexander Selkirk, or Mass Afuera Island $\left(\lambda=80^{\circ} 45^{\prime} \mathrm{W}, \phi=33^{\circ} 45^{\prime} \mathrm{S}\right.$, altitude of peak $\left.1653 \mathrm{~m}\right)$, situated some $900 \mathrm{~km}$ west of the coast of Chile.

A reconnaissance visit to Guadaloupe was made by Dr E. Mendoza and the writer in January, 1975, through the courtesy of the Mexican National Observatory and the Mexican Government and Coast Guard. The island is $38 \mathrm{~km}$ long in the north-south direction and $13 \mathrm{~km}$ wide east-west. The highest peak is located $8 \mathrm{~km}$ from the north end of the island and is the highest point on what appears to be the western rim of a ruined caldera, whose eastern half has disappeared into the sea. The height of the peak is rather low, but is the same as that of Mount Hamilton where the telescopes of the Lick Observatory are located. The island is located within the cold Alaska current which runs along the California coast and the height of the inversion layer is quite low, being, for example, only about $300 \mathrm{~m}$ at the time of our visit. Thus, the peak is probably above the inversion layer and its associated clouds most of the time. The number of clear hours should, therefore, be very high - comparable or superior to those at Mount Palomar in California and San Pedro Martir in Baja California. The prevailing wind is northerly and the general airflow around the island appears quite good as judged from satellite pictures (see, e.g., Watts 11.053.001). Airflow around the peak should also be good with wind directions from north through west to south. However, there is a possibility that winds from the northeast through southeast may be trapped in the interior of the caldera and force air cooled by contact with the slope up over the top of the peak. The island is presently uninhabited except for the staff of a meteorological station at the southern tip and a seasonal fisherman's camp on the southwest coast. A primitive access road runs from this camp to the peak, and a rough landing strip has been used for light airplanes. While too remote and difficult of access for present 
astronomical use, this site could be of considerable importance in the future, and a complete site testing program should be carried out to verify its quality.

As a result of arrangements made by Prof. Anguita and the University of Chile with the Chilean Government, a reconnaisance visit to Alexander Selkirk Island was made by Sr. J. Espinoza of the University of Chile and the writer in November, 1974, with transportation provided by the Chilean Navy and the Fisherman's Cooperative of the Juan Fernandez Archipelago. The island is located just within the western edge of the cold Peru current that flows along the coast of Chile, and the surrounding ocean is covered by the same inversion-layer cloud cover that blankets the coast. The island is approximately seven $\mathrm{km}$ wide and the high peak is located about one $\mathrm{km}$ from the upwind southwest coast, forming natural tower in the ocean. No information is available regarding the height of the cloud layer in the vicinity of Alexander Selkirk Island, and it was not known what percentage of the time the top of the peak projects above that layer. Only one night, November $21 / 22$, was spent on the peak. On this occasion, the cloud layer, which had enveloped the peak during the day, dropped a short distance (of the order of $100 \mathrm{~m}$ ) below the top at nightfall. However, this clearing lasted only until about midnight, after which the layer once more rose to shroud the peak. In order to determine the frequency of night time clearing, a recording hydro-thermograph was left on the peak and was operated, with financial support from the IAU, from November 21, 1974, until March 18, 1975, by one of the local fishermen, Sr. Nolberto Araya. Out of a total of 114 days (and nights) with observations during this period, low humidity, indicating emergence of the peak into the dry air above the temperature-inversion cloud-layer, occurred on only 8.5 nights. Typically, the relative humidity drops in the morning and rises again in the afternoon, remaining high $(\simeq 100 \%)$ all night, indicating that most of the time the peak is inside the cloud layer at night, and just below the bottom of the cloud layer during the middle of the day. On November 21,1974 no twinkling of the stars was visible to the unaided eye at altitudes of more than two degrees above the horizon; at this altitude only very slight twinkling was visible for Sirius. Thus, the seeing on this occasion was probably excellent. However, the percentage of clear weather appears to be too low for the site to have any practical value.

In the North Atlantic, several islands have the proper location and altitude of peak, including Fogo and Santa Antao in the Cape Verde Islands, Gran Canaria, Tenerife, and La Palma in the Canary Islands, the island of Madeira, and Pico in the Azores. (McInnes and Walker 12.082.033). Site testing has now been carried out by astronomers from the Royal Observatory Edinburgh on Fogo, Tenerife, La Palma and Madeira, and a reconnaissance visit to Pico was made in August, 1974, by the writer together with B. McInnes and P. Henley of the Royal Observatory Edinburgh.

Sites in the Cape Verde Islands appear to be ruled out by the prevalence of dust from the Sahara Desert. In addition, the seeing on Fogo is quite poor owing to the topographic structure of the island.

In the Canaries, Gran Canaria is excluded by the rather low altitude of the peak, the complex structure of the mountains which may disturb the airflow, and the great development of tourism which has resulted in extensive outdoor illumination and heavy air traffic to the island. On Tenerife, observations were made at the site of the Spanish observatory at Izaña $\left(\lambda=16^{\circ} 30^{\prime} \mathrm{W}, \phi=28^{\circ} 18^{\prime} \mathrm{N}\right.$, altitude $\left.2391 \mathrm{~m}\right)$ and on top of the high peak $(3718 \mathrm{~m})$. While the number of clear hours is high, the seeing at Izaña is not excellent owing to the disturbance of the high peak and to the concave shape of the island toward the direction of the prevailing wind. It seems likely that seeing conditions are very good on top of Pico del Teide, but the emission of corrosive vapors at the summit, which is still slightly active volcanically, probably rules out the construction of an observatory there. In addition, the island is rapidly developing as a tourist center and it appears that there could in the future be problems of light pollution and heavy air traffic.

Tests at Fuente Nueva $\left(\lambda=17^{\circ} 52^{\prime} \mathrm{W}, \phi=28^{\circ} 45^{\prime} \mathrm{N}\right.$, altitude $\left.2366 \mathrm{~m}\right)$ on the island of $\mathrm{La}$ Palma indicate excellent seeing and number of clear hours. No light pollution presently exists and there appears less likelihood of tourist or air traffic development than on Tenerife. All sites in the Canary Islands are affected somewhat by dust from the Sahara desert, but it appears that the number of nights so affected is only about $10 \%$ throughout the year. 
It is to be noted that JOSO (Joint Organization for Solar Research), which has been conducting a site survey for the location of a European Solar Observatory, has found excellent daytime solar seeing conditions on the top of Pico de Teide on Tenerife and at Roque de los Muchachos, near Fuente Nueva on La Palma (See: JOSO Annual Reports, and other papers referenced therein).

On Madeira, tests were made at Encumeada Alta $\lambda=16^{\circ} 56^{\prime} \mathrm{W}, \phi=32^{\circ} 46^{\prime} \mathrm{N}$, altitude $1784 \mathrm{~m}$ ). Here, the seeing was found to be better than at Izaña, but poorer than at Fuente Nueva, again probably for topographical reasons. The number of clear hours is slightly lower than in the Canary Islands, owing to the higher latitude. While the amount of light pollution is presently small, it is already about as much as one would want to accept at a site for a major observatory. Thus, future utility of this site would depend upon the possibility of light control on the island.

A comparison of the results obtained by the Edinburgh astronomers at lzaña, Fuente Nueva, Encumeada Alta, and Mauna Kea $\left(\lambda=155^{\circ} 28^{\prime} \mathrm{W}, \phi=19^{\circ} 49^{\prime} \mathrm{N}\right.$, altitude $\left.4200 \mathrm{~m}\right)$ is given in Table 1. In this table, photometric nights are defined as those with five or more consecutive hours with humidity $\leqslant 90 \%$, wind $\leqslant 25$ miles $^{-1}$, zenith $V$ extinction $\leqslant 0.5 \mathrm{mag}$, and cloud cover $\leqslant 5 \%$ above $30^{\circ}$ altitude and $\leqslant 15 \%$ above $10^{\circ}$ altitude. Useable nights are defined as those with 2 dark or one dark and one twilight hour as above. Seeing observations were made using the polar star trail method and are on the same system as those published by Walker (04.082.043, 06.082.071). For comparison, similar data are included for Junipero Serra Peak in California (Walker 04.082.018) and Cerro Tololo in Chile (Walker 06.082.071).

Table 1. Summary of observing conditions at island and coastal sites

\begin{tabular}{|c|c|c|c|c|c|c|c|}
\hline \multirow[b]{2}{*}{ Location } & \multicolumn{2}{|c|}{ Percentage of Nights } & \multicolumn{3}{|c|}{$\begin{array}{l}\text { Percentage of Nights with } \\
\text { Average Seeing as Indicated }\end{array}$} & \multicolumn{2}{|c|}{$\begin{array}{l}\text { Total Number of } \\
\text { Months Observed }\end{array}$} \\
\hline & Photometric & Useable & $\leqslant 1.0$ & 1."1-1."5 & 1."6-3."0 & Clouds & Seeing \\
\hline Fuente Nueve & 53 & 21 & 31 & 20 & 13 & 11 & 9 \\
\hline Izaf̃a & 57 & 17 & 8 & 24 & 27 & 18 & 13 \\
\hline Mauna Kea & $44 \dagger$ & 21 & 16 & 18 & 23 & 18 & 18 \\
\hline Encumeada Alta & 37 & 14 & 18 & 13 & 13 & 20 & 18 \\
\hline Junipero Serra & $42 \S$ & - & 26 & 38 & - & 26 & 26 \\
\hline Tololo & $42 \S$ & - & 24 & 32 & - & 23 & 23 \\
\hline
\end{tabular}

*Intervals covered by the observations are:

Fuente Nueva: Clouds, Aug-Sept 1972, Dec 1974-Aug 1975.

Seeing, Aug-Sept 1972, Dec 1974-June 1975.

Izaña: Clouds, Jan-Nov 1972, Feb-Aug 1975.

Seeing, Jan-Nov 1972, Feb-Mar 1975.

Mauna Kea: Clouds and Seeing: Aug-Sept 1973, Feb 1974-May 1975.

Encumeada Alta: Clouds, Aug-Nov 1973, Jan 1974-Apr 1975.

Seeing, Aug-Nov 1973, Jan 1974-Feb 1975.

Junipero Serra: Clouds and Seeing, Aug 1965-Oct 1967.

Tololo: Clouds and Seeing, Oct 1968-Aug 1970.

Differences in intervals for clouds and seeing results from incomplete reduction of seeing observations.

† According to Morrison et al. (09.009.023), 56\% photometric between Jul 1969 and Feb 1973.

$\S$ For these sites, photometric nights are nights with $\geqslant 6^{\mathrm{h}}$ continuous with zero cloud cover above $15^{\circ}$ altitude.

The summit of Pico $\left(\lambda=28^{\circ} 24^{\prime} \mathrm{W}, \phi=38^{\circ} 27^{\prime} \mathrm{N}\right.$, altitude $\left.2351 \mathrm{~m}\right)$ consists of a caldera, some $30 \mathrm{~m}$ deep and $500 \mathrm{~m}$ in diameter with a secondary cone rising an additional $100 \mathrm{~m}$ above the rim of the caldera on the north-east side. While volcanic activity appears to have ceased in 
the caldera, fumarolic activity occurs at the top and on the sides of this more recent cone. To have adequate space, an observatory would have to be located on the southwest rim of the caldera, with the possibility of disturbance of the airflow by the summit cone and the caldera when the wind is from northerly directions. No information is available about the percentage of clear weather on the summit and, in view of the fairly high latitude, this question should be investigated before a decision to undertake a full scale site testing program is made.

The result of these studies is that there is one island - Guadaloupe - in the Pacific of possible interest as a dark sky site, on which tests should be conducted to verify its quality. In the Atlantic, the islands of Tenerife and Madeira are of interest as potential sites, while La Palma appears to be outstanding and should certainly be protected for future astronomical use.

\section{Present Information Regarding Potential Sites on Continental Coasts}

It appears that there are probably no first class potential sites along the west coast of Australia owing to the lack of coastal mountains of sufficient height. Coastal sites along the coast of North Africa may be ruled out by the Sahara dust that affects locations in the Cape Verde and Canary Islands. From what is known at present, it appears likely that a number of additional sites in Chile similar in quality to Tololo, La Silla, and Las Campanas could be found. In California, large areas of the state are eliminated from consideration by light pollution (Walker 04.082.043, 10.082.108). The best remaining coastal site is Junipero Serra Peak. This site is of first quality and should be protected for astronomical use. Little is known concerning the possibility of locating additional sites in Baja California. Except at the extreme southern end, the high peaks occur toward the eastern edge of the peninsula and this, together with the northerly direction of the prevailing wind, may decrease the probability of finding sites with laminar airflow. Studies of this region should be made before light pollution problems develop.

With the very generous support of the Max-Planck Institute and the South African Council for Scientific and Industrial Research, reconnaissance visits were made by the writer to the Gamsberg observing site of the Max-Planck Institute and other possible sites in South West Africa and South Africa during August, 1974. On the basis of this visit, it appears that while there are several potential sites in South West Africa, the best of these is the Gamsberg, the next best probably being portions of the Naukluft Plateau. Data regarding meteorological and observing conditions at the Gamsberg have been published by Elsässer (1972, Jahrbuch der Max-Planck Gesellschaft p. 84) and by Birkle et al. (1976, Astron. Astrophys., in press). Sites in this region have the advantages of very high transparency, and annual average number of clear hours-comparable to that of sites in Chile, but with an annual variation in this number which is the inverse of that found in Chile. In Chile, the highest number of clear nights occurs in the period from about October through April. In South West Africa, the maximum number occurs from about April through September, making sites there particularly valuable for studies of the Galactic center. The Gamsberg site is owned by the Max-Planck Institute, which welcomes the installation of telescopes on the site by other observatories. The site is located some $120 \mathrm{~km}$ southwest from Windhoeck, the nearest large city, and at present has no light or atmospheric pollution problems. All of the potential sites in South West Africa are located some $160 \mathrm{~km}$ inland since the first high mountains are separated from the coast by the Nambib Desert. It is therefore not entirely clear whether the seeing at these sites is comparable to that of the highest quality island and coastal sites discussed earlier. Seeing measurements have been made at the Gamsberg, but using different techniques from those used at the sites previously discussed, so that direct comparison is difficult. Birkle et al. (1976) find from measures on the Gamsberg and on La Silla using the same techniques that the average seeing is similar at the two locations. However, observations by the spectroscopic observers at La Silla of the image size in seconds of arc (Birkle et al., 1976), which should be on the same system as the polar star trail seeing results of Walker (06.082.071) at Tololo, indicate that the seeing at La Silla is somewhat poorer than at Tololo - a difference which could result from effects of the local topography. In any case, the Gamsberg appears to be an important potential site whose preservation for future international astronomical use should be supported.

Thus, present data indicate that there are two potential sites in the coastal areas bordering the mTs airmass source regions particularly deserving of protection: Junipero Serra Peak in California and the Gamsberg in South West Africa. 


\section{Other Areas}

Ultimately, we shall want to have seeing and other observing data for sites in the other areas of the world with low cloud cover outside those discusesed in the preceeding sections. Since a general reconnaissance program is not feasible, it is recommended that as astronomers in different countries find opportunity to study sites in their territories, they adopt instruments and techniques of measurement used at sites already tested so that their results can be directly compared with those from these sites, and that they publish the results of their investigations in detail. The Commission will appreciate being informed regarding the planning and results of such programs.

\section{FUTURE COMMISSION ACTIVITY AND RECOMMENDATIONS}

While certain Commission activities and recommendations have been discussed in this report, it is clear that much remains to be decided. It is hoped that at the next General Assembly the Commission can discuss further the problems of sites to be recommended for investigation and/or protection, allowable amounts of luminous and radio-frequency interference, recommendations regarding protective measures to be adopted, and the optimum use of the resources of the Union to achieve the goals of the Commission. 